\title{
The Influence of Human Capital Development Strategies on Competitiveness of Small and Medium-Sized Practices in Uganda
}

\author{
Albert Otete \\ Doctorate Candidate, University Institute for European and International Studies, Heyendallaan 64646 Kerkrade, \\ Netherlands and ESAMI Business School PO Box 3030 Arusha, Tanzania
}

\begin{abstract}
Purpose: Small and medium-sized practices (SMPs) in Uganda play an important role in providing professional services to Ugandan organizations, especially the Small and medium-sized entities (SMEs). The increasing number of SMPs in Uganda means that each firm must devise means of outcompeting the others. This study aimed to ascertain how human capital development strategies may be influential in the competitiveness of SMPs in Uganda. Human capital development strategies are schemes or programmes by which SMPs train their partners and professional staff to offer effective and top-quality work and promote the trust and confidence of their clients. There is also an ethical requirement to undertake work with due care and diligence.

Methodology: The SMPs in Uganda were selected randomly to respond to a structured questionnaire. A total of 124 responses were used for data analysis representing almost $90 \%$ of the sample size.

Results:

Confirmatory factor analysis was used to determine how human capital development strategies influence the competitiveness of SMPs in Uganda. There was evidence that human capital development strategies significantly influence the competitiveness of SMPs in Uganda. Whereas there were only 18 out of 124 SMPs in Uganda that are part of an Accounting Association or Network, evidence showed that there was a significant difference between the two groups in terms of the composite human capital development index and development spend. However, there was no significant difference in terms of development days allocated to assistants, supervisors or partners. Over $60 \%$ of the SMPs in Uganda spent less than USD 2000 per annum on human capital development programmes. The SMPs in Uganda were put into five groups depending on their level of spend. Evidence showed there was significant difference between SMPs that spent less than USD 1000 per annum and those that spent over USD 3000 per annum, with the latter showing higher levels of competitiveness.

Significance of study: This study will supplement the worldwide SMP surveys conducted by the International Federation of Accountants, the latest of which was conducted in 2018. In particular, the study reveals a need for SMPs in Uganda to invest more days (at least 20 per professional staff) and money on human capital development programmes. In addition, the argument for an outputs-based continuing professional development regime is supported. Whilst SMPs have invested time/money (inputs-based approach) on continuing professional development, it has not yet translated into higher levels of competitiveness with $96 \%$ of SMPs in Uganda earning less USD 1million in annual fee revenue.
\end{abstract}

Keywords: Human capital, development, strategies, competitiveness, Small and Medium-sized Practice

\section{Introduction}

The Small and medium-sized practices (SMP) Committee of the International Federation of Accountants (IFAC) has developed a Global Knowledge Gateway that can be accessed by SMPs worldwide. The definition of SMP remains controversial, but for purposes of this study refers to all regulated accounting firms other than the Big-4 and the SMPs typically have Small and Medium-sized Entities (SMEs) as their main client base.

Among the publications developed by the SMP Committee is the survey reports that highlight the profile of those accounting firms that fall into this category. The other publications include the Guide to Quality Control for SMPs, Guide to using International Standards on Auditing (ISAs) in the audit of the financial statements of SMEs and the Guide to Practice Management for SMPs. The idea is that SMPs do not have the support of a regional or headquarters (like the Big-4) office dedicated to production of technical materials. The Global Knowledge Gateway is expected to provide useful materials that SMPs can use as part of their human capital development strategies, especially in the areas of audit/assurance and financial reporting.

In May 2011, the Pan African Federation of Accountants (PAFA) was formed with the main objective of promoting the profession of accountancy on the African continent. This was motivated by the discovery that some challenges facing the accountancy profession, especially among SMEs and SMPs could be significantly different from the rest of the world despite that all members are affiliated to IFAC. The PAFA provides technical assistance and capacity building to its 53 members. One of such members is the Institute of Certified Public Accountants of Uganda (ICPAU) which is responsible for regulating and maintaining the accountancy profession in Uganda. ICPAU celebrated 25 years of existence in 2017 and regulates over 200 SMPs in the country. In the Ugandan auditing market, the Big-4 have remained dominant in major areas. Among the 15 companies listed on the Uganda Securities Exchange, 13 of them were audited by the Big-4 earning audit fees of over USD 
3.3million. The two SMPs that participated earned only $1 \%$ of that fee. In the area of Ugandan commercial bank audits for the year 2017, the Big-4 garnered 24 (73\%) out of the 33 audits, while the SMPs had $9(27 \%)$ of them. This shows that SMPs need to gradually increase their level of competitiveness if they are to move up the ladder. As professional accounting firms are knowledge-intensive, this study aimed to ascertain the influence of human capital on competitiveness of SMPs.

\section{Literature review}

\subsection{Concept of competitiveness}

Competitiveness is a position that puts a firm in a superior business advantage vis-à-vis its peers or competitors. There have been varied measures and definitions of competitiveness put forward in theory. A situation of perfect competition is rare in that not all players in the industry will have the same information at the same time in the same magnitude. Rather the increased number of players in the industry leads to higher levels of imperfection and competition that lacks a clear format or pattern (Clark, 1940). Most of the non-specialized industries have situations where the producers have almost a standardized product. This is true of the accounting firm industry where the external audit opinion on a set of financial statements follows a similar format prescribed by IFAC and the only variation is in the contents. Given that the product is standardized and buyers are knowledgeable of the measures of quality, an accounting firm has to invest in product development and marketing. Market segmentation, process improvement and innovation are some of the ways of standing out of the crowd (Alderson \& Cox, 1948; Schumpeter, 1942). The challenge of differentiation is more prevalent among the SMPs than the bigger firms.

The bigger firms have maintained a monopolistic stature even as far back as the era of the Big- 8 and the degree of competitiveness of the audit industry was pegged on the fee data. The fees earned by each firm is a function of the unit price and the quantity of audits purchased by the clients (Simunic, 1980). Big-8 firm concentration ratios among the auditee that were publicly listed on the stock exchange positively correlated with the size of the auditee company. Auditor size had a positive influence on audit quality, which in turn increased confidence of stockholders (DeAngelo, 1981). The output from an external audit process is the audit opinion on a set of financial statements. The inputs to this process are the labour hours per staff who vary in position ranging from partner, manager, supervisor and assistant (O'Keefe, Simunic, \& Stein, 1994). Therefore, human resources are central to the outputs produced by accounting firms whether it is the traditional audit/assurance line of business or tax and consulting.

Whilst the products from accounting firms appear to be standardized, competitiveness is about how the resources are transformed into value in a manner that is better than direct competitors. To determine competitiveness of a firm, its level of productivity has to be compared against peers. A study of accounting firms in the UK revealed that Big-4 had substantially high productivity using number of partners, number of professional staff and annual firm revenues as indicators (Djerdjouri \& Kandiel, 2013). The smaller and medium firms had productivity index of 0.58 meaning there was room to earn more revenues with same human resources. This evidence supports the view that Big-4 should be studied separately from SMPs to avoid large variances and outliers posed by the Big-4 numbers. Competitiveness can also be gauged through market share information, if available. Auditor concentration ratio for Big-4 audit of companies listed on Malaysian bourse was $75 \%$ and internationally affiliated firms also occupied the number 5-10 positions (Mohamad-nor, 2015). The indicator of concentration was at annual audit fees level, which information is normally disclosed in the audited financial statements of the listed companies.

\subsection{Concept of human capital development}

Employees are one of the factors of production in any organization. The acquisition of new employees through a recruitment and selection $(\mathrm{R} \& \mathrm{~S})$ process is aimed at selecting the best candidate from the market so that they can reinforce existing manpower with the view that they may add value to the firm (Golnik, 2014; Mahmood, Iqbal, \& Sahu, 2014; Ofori \& Aryeetey, 2011). The objective of recruitment is to get people who will be relevant to that specific firm in as far as their organizational objectives are concerned.

Training of employees is crucial to stem the negative effects of skills and knowledge obsolescence. Although employees may have diverse academic and professional qualifications, there is a risk of that previously acquired knowledge may be superseded due to the dynamic environment. Many writers continue to agree that human capital is the most significant asset. Additional investment in training leads to an increase in employee performance. In the case of an Indian IT firm, one additional training course improved the employee performance by 2\% (Bapna, Langer, Mehra, Gopal, \& Gupta, 2013). The limitation of the study by (Bapna et al., 2013) was its confinement to only one firm and although that firm is reported to have one of the best human capital practices, one cannot determine how it compared against peers in the same industry and how it translates into a competitive advantage.

Accounting is a global profession and the introduction of International Education Standards (IES) to be 
followed by all members of the International Federation of Accountants (IFAC) is meant to extend that globalisation agenda. The IES are developed by the International Accountants Education Standards Board (IAESB) of IFAC. The CPDs are a life-long annual requirement for all professional accountants, failing which sanctions are imposed, including deregistration as a professional. IES No.7 stipulates 120 hours of CPD over a three-year period of which half must be verifiable. This is broken down into 20 hours per annum and IFAC member bodies are to track/measure the learning outcomes. IFAC developed statements of member obligations (SMOs) of which quality assurance and international education standards are the first and second obligations (IFAC, 2012).

(De Lange, Jackling, \& Suwardy, 2015) argued that globally cast CPD agenda had fallen short of the needs of professional accountants in emerging economies, and thus calls for a diverse array of CPD activities have since emerged. (Berg, 2007) also questioned the input-based approach which forces professional accountant to simply comply with the 20-hour per annum limit, but learning may not have taken place. He supports the outputbased approach which focuses on demonstrated learning outcomes, for example, tests, peer reviews and selfassessments. IAESB acknowledged this and allows member bodies of IFAC to choose either the input-based, output-based or a triangulation of both methods. Professional accountants are disillusioned by the existing CPD due to lack of noticeable increase in their employability nor income. Internet or self-study options for CPDs can be explored encompassing varying levels of difficulty and subject matter. (Wessels, 2007)

Continuing Professional Development (CPD) programmes in the professional accounting industry is used by the accounting regulatory bodies to measure the extent of development for their members and issue practicing certificates or renew them. CPDs offering should squarely fall in ambit of the practicing professionals (Boud \& Hager, 2012). Earlier studies by (Webster-Wright, 2009) found that the existing CPD regime had not fostered learning but just an accumulation of attendance hours. However (Fenwick, 2009) was more optimistic citing innovations like self-administered tests and learning logs that had been introduced by some professional accounting regulatory bodies for their members. (Boud \& Hager, 2012) agree that changing the CPD mindset will take time. For SMPs, this change is urgent to plug the perception that practitioners and their professional staff lack necessary skills to deliver quality work, especially auditing of financial statements of public interest entities (PIEs). The CPDs are meant to increase the level of competence of the practioner. Verifiable and structured CPDs enhance the professional value coupled with support through networking groups (Bradley, Drapeau, \& DeStefano, 2012)

In Nigeria, the training of professional accountants was insufficient and a number of members required retraining (Romanus \& Arowoshegbe, 2014). The accounting curriculum at University-level was in dire need for restructuring to meet needs of modern trends in accountancy. A similar problem was cited in a Kenya study where technical competence was ascertained only through paper-based examinations (Ng'ang'a, 2014). The view is that even after passing tertiary-level examinations, an additional 3-5 years would be required for practical field training of a holistic accountant. Compliance with the CPD requirements is essential for the professional accountants in respect to corporate reporting, which is an output that is visible to stakeholders and display the quality of the professional accountants from that firm and enhance or destroy its reputation (Kaspina, 2015). In the same study, it was observed that to achieve high quality in corporate reporting in a firm or organization, the CPDs should not only be for top-level accountants but also their junior counterparts.

The IAESB sets guidelines for CPD that professional accountants and their regulators should follow if they are to be trusted as reservoirs of knowledge to the business community globally. (P De Lange, Jackling, \& Suwardy, 2012) argued that CPD should be tailored to the specialised roles that professional accountants play and their levels of responsibilities to be of continuous relevance to the needs of the clients/employers (De Lange et al., 2012). In particular, International Education Standard (IES 7) touches on CPD. (De Lange, Jackling, \& Basioudis, 2013) and team participated in a project to revise all the eight IES in 2009; which went a distance to address the gaps that existed in the prevailing education standards for professional accountants. The new IES became effective in 2014 and (De Lange et al., 2015) suggest that further research should be undertaken to evaluate how IFAC bodies and professional accountants have implemented those revised standards in their respective jurisdictions. In one Indian IT firm, new employees undergo mandatory 26-week foundation technical course tailored to the needs of the firm and its customers. This training is to bridge gaps in the theoretical education those employees may have attained at school or University (Bapna et al., 2013). Auditor training is important to avoid dysfunctional auditor behavior (Svanström, 2016)

\section{Methodology}

\subsection{Research design}

The sampling frame is a list of the 213 SMPs in Uganda (ICPAU, 2017) and it excludes the Big-4. Based on that target population, the sample was determined to be 140 (Krejcie \& Morgan, 1970). The SMPs were listed alphabetically and given numbers from 1-213. Random numbers were generated and the top 140 random numbers were used to select the SMPs to contact for purposes of completing the structured questionnaire. A 
cross-sectional study design was used to enable collection of data at a given point in time. This was preferred to time-series which could disadvantage newly established SMPs. A quantitative research approach was adopted.

\begin{tabular}{|c|c|c|}
$\begin{array}{c}\text { Human } \\
\text { Capital } \\
\text { Development } \\
\text { Strategies }\end{array}$ & $\begin{array}{c}\text { Competitiveness of } \\
\text { Small and Medium-sized } \\
\text { Practices } \\
\text { in Uganda }\end{array}$ \\
\cline { 2 - 2 } & Figure 1: Conceptual framework
\end{tabular}

\subsection{Variables description}

The dependent variable is the competitiveness of the SMPs in Uganda. The factors of competitiveness are operationalized by a rating of factors relating to (a) portfolio base of clients (b) firm being on pre-qualified list of suppliers (c) success in bidding for new clients (d) display of human capital through publicity and (e) rating by the regulatory after mandatory quality assurance reviews. These items were selected because they could have a bearing on annual revenues earned by the firm. Overall, the level of competitiveness was measured using clients billed per annum and resultant annual revenues earned in a year. Annual fees earned (revenue) was used in a study of the Malaysian audit industry although the focus was only companies listed on the Kuala Lumpur Stock Exchange (Abidin \& Mohamad-Nor, 2015). Annual revenue measure was also used to assess productivity of 43 accounting firms in the United Kingdom from 2009-2012 (Djerdjouri \& Kandiel, 2013)

The independent variables are the human capital development strategies implemented by SMPs in the technical business line areas of (a) audit/assurance (b) taxation and (c) consulting. The other independent variables are the general/soft skills that SMPs may adopt. The adoption of these variables is in line with typical accounting firm business segmentation (Statista, 2017). This study also examines the extent to which human capital development strategies are influenced by membership to an accounting association or network (AAN) where one of the perceived benefits cited among US small firms was access to joint conferences and technical training (Bills, Cunningham, \& Myers, 2015). Studies have shown that membership to AAN lead to higher audit quality, and hence audit fee revenue (Bills, Walton, Hayne, \& Stein, 2018; Mao, Qi, \& Xu, 2017).

\subsection{Research objectives and hypothesis}

i. RO1: To determine how human capital development strategies influence the competitiveness of SMPs in Uganda. (Null hypothesis $H_{0}$ : Human capital development strategies have no significant influence the competitiveness of SMPs in Uganda)

ii. RO2: To determine how human capital development strategies of SMPs in Uganda differ depending in membership to AAN. (Null hypothesis $H_{0}$ : Human capital development strategies do not differ significantly with membership to AAN)

iii. RO3: To determine how human capital development strategies of SMPs in Uganda differ depending annual investment in development programmes. (Null hypothesis $H_{0}$ : Human capital development strategies do not differ significantly with annual investment in development programmes)

The measure of the level of competitiveness of the SMPs based on total clients billed per annum is calculated using a maximum of 90 clients for each of the three business lines of audit/assurance, tax and consulting. This corresponds to 270 clients per annum. This is then divided equally among the three categories of low, medium and high meaning 90 clients per band. Interpretation: $>90$ clients (low), 90-180 clients (medium) and $>180$ clients (high).

The determination of the level of competitiveness of the SMPs based on total annual revenue earned by the firm, in USD is calculated using a product of maximum of 270 clients per annum and a maximum average fee of USD 11250 per client. This corresponds to about USD 3million in revenue per annum for the top most SMP in Uganda. This is then divided equally among the three categories of low, medium and high meaning USD 1 million per band. Interpretation: > USD 1 million (low), USD 1-2million (medium) and >USD2million (high).

The hypothesis testing was done through Confirmatory Factor Analysis (CFA) in which the observed variables were reduced into a simple structure with the aid of factor rotations. Eigenvalues cut-off of 1.0 helped to determine the maximum number of factors that should be used to avoid a complicated model. Structural Equation Modeling (SEM) was preferred to display the model diagrammatically and show the measurements and structure. Fit indices were used to ascertain the level of fitness between the data and hypothesized model. Regression analysis was also applied to identify lines of best fit. Leverage plots and other methods were used throughout the testing to ensure that the assumption of normality was maintained. One-way Analysis of variance (ANOVA) was used to test differences between groups and Tukey's post-hoc honestly significant difference (HSD) helped pin-point which groups had significant differences. 


\section{Results and discussions}

4.1 Descriptive statistics

The overall response rate (ORR) was 89\% (124 responses out of 140 SMPs selected as the sample size). Out of the 124 firms, 106 of them are not members of an Accounting Association or Network (AAN) representing 85\%. The average number of years in operation of the SMPs was 10 years with $60 \%$ of them below the average meaning that the number has more than doubled in the last decade. 10 SMPs had 3 or 4 partners, $64(52 \%)$ had two partners while $50(40 \%)$ of them were run by a sole practitioner. In terms of total human capital, the average firm had 11 full-time professional staff (at partner, supervisor and assistant level) and the SMPs employed about four part-time staff during a year. On average, four professional staff possess the CPA qualification while two have the Chartered Accountant accreditation (mainly ACCA). Of the 11 full-time professional staff, six of them hold Bachelor's degree while two also have Masters' level of academic achievement. Doctorate-level are fewer and cannot meaningful be averaged per SMP but the data showed that 10 firms had at least one professional staff with Doctorate academic status. In terms of the main independent variables of this study average annual development days was 15 for partners, 12 for supervisors and 11 for assistants. The average spend on human capital development programmes was USD 1984 per annum with a minimum of USD 500 and maximum of USD 4500.

\subsection{Exploratory factor analysis}

The data collection instrument (questionnaire) is reliable meaning that its administration to another sample similar of SMPs from the same population would yield almost similar results. The Cronbach alpha $(\alpha)$ score for human capital development items on the Likert scale is 0.90 while that for competitiveness is 0.75 . These were both above the recommended threshold of 0.60 . The sample is considered adequate using the Kaiser-MeyerOlkin (KMO) statistic of 0.82 and indicated suitability of the data for confirmatory factor analysis. The KMO for each variable is calculated and none of them is below the recommended threshold of 0.60 . Before proceeding any further with hypothesis testing, normality tests were conducted. The skewness and kurtosis of the variables were examined and results showed that individual variables were negatively skewed meaning that most scores had a mean $>$ median. The highest kurtosis score was 4.52 which is below 9.0 (considered the range for normality). A combined test of both skewness and kurtosis was undertaken and the probabilities were significant in that the probabilities of a chi2 greater that the critical values was less than an $\alpha$ of 0.05 , with the exception of three variables of consulting training, human capital publicity and portfolio base of clients. Nonetheless, all variables were included into confirmatory factor analysis given that the correlation matrix revealed moderate to high positive correlation among variables. The risk of multicollinearity of independent variables is low. The Variance Inflation Factors (VIF) of each of those variables was determine and they ranged from 1.44 (lowest) to 5.52 (highest) which is below the recommended threshold of 10.0. Cook's distance was deployed to examine influence of outliers. 10 observations had a Cook's distance greater than $4 / n$ (where $n=124$ observations). Robust regression analysis was used to ensure that those few outliers do not have a significant influence on the model.

\subsection{Confirmatory factor analysis}

Out of the initial 14 factors (based on the number of variables under study), only 8 of them were retained because the remainder were not full rank. However, only two factors had an Eigenvalue $>1.0$ and a scree plot of all Eigenvalues revealed an elbow between the second and third factor. These two factors explained $87 \%$ (Factor $1:$ Eigenvalue $=5.228$, proportion $68 \%$ and Factor 2 : Eigenvalue $=1.467$, proportion $19 \%$ ) of the variance in the observed variables. One of the independent variables (professional accounting competence through CPA, ACCA or any other relevant course) was dropped as it had a factor loading of less than 0.50 . This meant that 13 out of 14 variables proceeded (Appendix Table 2) to the next stage of modelling. However, the said professional accounting competence is not lost completely as the examinations are often supplemented by on-the-job training through other development strategies, especially International Standards on Auditing (ISAs) and those for International Financial Reporting Standards (IFRSs) which are a critical part of the CPA and ACCA examinations.

Orthogonal varimax rotation was used to arrive at a simple structure. Most of the SMPs indicated that they deploy moderate to high frequency of development programmes as depicted by the mean scores of at least 3.0 out of 5.0. The SMPs also felt that the observed measures were moderate to high level of criticality to their competitiveness. The scores by the SMPs were not spread out as evidenced by standard deviations of the mean of no more than 1.30. If standard deviations had exceeded 2.0, it would imply a presence of highly significant outliers which is not the case in this study. The mean scores for each of the factors were high implying that the SMPs have almost similar views on the importance of those selected development programmes (factor mean $=$ 3.90 out of 5.00 ) and the criticality of the selected competitiveness (factor mean $=3.71$ ) indicators. 


\subsection{Path analysis for human capital development}

Within the correlation matrix (Appendix Table 1), there is a very high positive correlation between development strategies applied by SMPs for training in ISAs and those for IFRSs is 0.888 . In addition, the orthogonal rotation (Appendix Table 2) shows that development strategies for ISAs and IFRSs were rated high by SMPs with a mean of 4.11 and 4.22 respectively. Consequently, the two variables were paired up in the model to create a new variable called audit assurance. This is to make the model simpler but also makes sense in reality. In order to provide assurance on a set of financial statements in accordance with ISAs, the SMP must be conversant with IFRSs. Without an understanding of IFRSs, there is a risk that the partner of an SMP will make a Type II error on the audit opinion (mistakenly stating that financial statements show a true/fair view, yet it is false). A Type I error could also occur when the audit opinion is qualified, yet it should not have been probably because the partner misinterpreted judgements accepted under IFRSs. Therefore, development strategies for ISAs and IFRSs tend to move in tandem in most SMPs.

A number of SMPs also incorporated soft skills in their development strategy. In this study, training on writing and presentations, networking, selling, people and leadership skills have been grouped under new variable general_soft skills as they support the delivery of the technical products and services that the SMP provides to its clients and can be a source of competitiveness. In this age of information technology, development strategies involving sharpening IT skills and deployment of a variety of Computer-Aided Auditing Techniques (CAATs) have become commonplace.

A Confirmatory Factor Analysis (CFA) using Structural Equation Modelling (SEM) for the Development construct is shown under Appendix Figure 1. SEM is a technique that has become popular for social researchers because it is an improvement from the traditional linear regression. SEM incorporates both a measurement component (the path coefficients of observed variables) and the structural component (the relationship between latent/unobservable variables/constructs. Given that the questionnaire is a multi-item instrument, SEM was considered the preferred technique to develop a model to match the collected data to the underlying theory about human capital development and competitiveness - this is the model fit. In order to conclude whether a model fit is "good or bad", researchers have come up with fit indices. However, there have been debates on which fit indices to report on and what threshold amounts to "good fit or bad fit". In this study, specific guidance on SEM and commonly used fit indices of Root Mean Squared Error of Approximation (RMSEA), Standardized Root Mean Squared Residual (SRMR), Comparative Fit Index (CFI) and Tucker-Lewis Index (TLI) are adopted (Hooper, Coughlan, \& Mullen, 2008). These common indices have become part and parcel of most of the renown statistical software like STATA15®

RMSEA is an index (ranging from 0.0 to 1.0 ) that shows how a model with selected parameter estimates fit the population matrix of covariance. An index of less than 0.06 is considered a good fitted model (Li-tze Hu \& Bentler, 1998). The advantage of RMSEA is that is favours a model with as few parameters as possible and penalized for complicated models (with many parameters). This makes it one of the favourite indices since readers and researchers would prefer a simpler model. The SRMR (ranging from 0.0 to 1.0) on the other hand will be lower for models with higher number of parameters and large sample sizes. The SRMR is calculated based on the scores of each Likert-scale per respondent and an index of less than 0.08 is considered good (Li-tze $\mathrm{Hu} \&$ Bentler, 1998) with 0.00 showing perfect fit. The CFI and TLI compare the fitted model against a nullmodel (which assumes a worst-case scenario where all measured variables are uncorrelated, hence showing a correlation of 0.00). CFI and TLI favour simpler models and can work well with samples of less than 200 (like in this study). Indices approaching 1.00 represent prefect fit but a figure of 0.96 or higher are good enough (Li-tze Hu \& Bentler, 1998; Li - tze Hu \& Bentler, 1999)

Appendix Figure 1 shows that high and positive coefficients of each of the variables within the fitted model. For example, audit_assurance has a slope of 0.68 on the line of best fit and a y-intercept (constant) of 4.4. This means that for every additional score on the auditassurance ratings, the construct of Development increases by $68 \%$. There are also covariances between error terms in the observed variables (shown as curved lines between the error terms on Appendix Figure 1). These reflect the variances that are not related to the main construct of Development. These covariances were introduced to improve the model fit but also ensure less variance remained unexplained.

The end result of the CFA revealed a RMSEA $=0.000$ and a SRMR $=0.000$ indicating perfect fit. The CFI and TLI are both 1.000 which again show perfect fit. The coefficient of determination (CD or $\mathrm{R}^{2}$ ) shows that $82 \%$ of the variation in the construct of Development can be predicted from the observed variables.

\subsection{Path analysis for competitiveness}

SEM for the Competitiveness construct is under Appendix Figure 2. Three of the dependent variables were combined to form a new variable named active_client. These variables included (a) portfolio base of clients (b) bid or proposal success and (c) pre-qualification listing. It is a hierarchical formation whereby SMPs attempt to outcompete each other and be one of the preferred suppliers of professional advice. If successful, the SMP is 
included on a list of pre-qualified suppliers. The second step involved clients asking SMPs to bid for jobs either through selective or open bidding. Whatever the method, the SMP aims to increase its probability of success and this can only be achieved through possession of a competitive edge. One of the challenges cited in previous SMP surveys was that firms were unable to distinguish themselves from the competitors (IFAC, 2017). Once the SMP has increased its bid success ratio/rate, its portfolio base of clients keeps growing which to a great extent guarantees a revenue stream upon execution of the contracts. It is on the basis that these three variables involve interaction with clients at pre-qualification, bidding and contract stages that the tag active client has been coined for them. On the other hand, whereas SMPs scored display of human capital capabilities in brochures and online media, this is passive. Potential clients may or may not invite the firm for pre-qualification or bids. Nonetheless, it is still critical that the SMPs capabilities are displayed. With regard to the quality assurance ratings, this is an annual exercise undertaken by ICPAU using a risk-based approach. The rating is primarily focused on adherence to the ISAs and Code of Ethics and a score is provided to the firm accompanied by a detailed report of areas of weaknesses. These ratings are confidential and private to the specific SMP but clients may ask for such ratings during pre-qualification or bidding process. Therefore, SMPs do agree that these quality assurance rating to some extent a sign of competitiveness.

Appendix Figure 2 shows that the active_client variable contributes significantly to competitiveness of SMPs with a coefficient of 0.97 and a y-intercept (constant) of 5.6. The second most important variable is comp_media with a coefficient of 0.58 . Ultimately, the CFA also had a RMSEA $=0.000$ and a SRMR $=0.000$ which have same conclusions with those noted under Development construct. The same applies to the CFI and TLI which were both 1.000 . The coefficient of determination $\left(\mathrm{R}^{2}\right)$ shows that $95 \%$ of the variation in the construct of Competitiveness can be predicted from the observed variables.

\subsection{Research Objective (RO1) - to determine how human capital development strategies influence the competitiveness of SMPs in Uganda}

Appendix Figure 3 shows the path analysis depicting the influence of the independent latent variable on the dependent latent variable. It is a merger of Appendix Figures 1 and 2, although some of the path coefficients changed but remained positive. Standardized path coefficients show the extent to which a particular variable loads onto the latent variable (construct). The reason some of these path coefficients changed the addition of the covariance between Development and Competitiveness which has a coefficient of 0.44 , meaning that $44 \%$ of the variance in the dependent latent construct can be explained by the variance in the independent latent construct. Although the coefficient of determination $\left(\mathrm{R}^{2}\right)$ shows about $98 \%$ and $\mathrm{SRMR}=0.057$, the other fit indices were a "bad fit" with a chi2 $(9$ degrees of freedom $)=33.710$. The RMSEA $=0.149>0.06$ which shows not a "good fit" (Li-tze $\mathrm{Hu} \&$ Bentler, 1998). The CFI $=0.928$ and TLI $=0.833$ are both below the 0.96 recommendation. Modification indices are recommended to identify potential areas for improvement in the model fit but should be applied cautiously with theoretical justification (Hooper et al., 2008). The modification indices obtained were not large enough and the available covariances that could be added were not theoretically sensible, especially between error terms. As an alternative way to test the model fit, a robust regression analysis was run using a single index for each of the Development and Competitiveness factors as shown in Appendix Table 3.

The F-test shows that the regression model was significant at $\mathrm{p}<0.05$. The result for Research Objective RO1: $F(1,1,122)=9.41, p=0.00<0.05$, hence the null hypothesis is rejected. Appendix Figure 4 shows that the test of normality was still maintained with leverage (measure of deviation from the mean) being less than 0.1 and the normalized residual squared of less than 0.1 .

In conclusion, there is evidence that human capital development strategies influence the competitiveness of SMPs in Uganda.

\subsection{Research objective (RO2) - to determine how human capital development strategies of SMPs in Uganda differ depending in membership to AAN}

There were 106 SMPs that were not members of AAN, while 18 has such membership. In analysing whether there are significant differences, the human capital development strategies included in the examination were (a) the composite index for Development (FDevp) based on Likert-scale scores (b) annual development expenditure in USD (c) development days for assistant-level staff (d) development days for supervisor-level staff (e) development days for partners.

The Tukey's honestly significant different (HSD) pairwise comparisons were used with a studentized range critical value $(0.05,2,122)=2.7996$ for each of the measurements above and the detailed results shown under Appendix Table 4. The F statistic for the composite Development index $(F D e v)$ is $\mathrm{F}(1,122)=8.74, \mathrm{p}=$ $0.004<0.05$. This means that there is 8.74 variability between the two groups than is the variability within the groups. The F statistic for the Development spend is $\mathrm{F}(1,122)=13.05, \mathrm{p}=0.004<0.05$, hence an even higher variability between the two groups. Another interpretation is to use the HSD critical value of 2.7996. The HSD for FDev is 4.1802 while that for Development spend is 5.1091. Both these values are higher than 2.7996 which 
shows a significance at 0.05 . The other HSD values are below the critical value, hence not honestly significantly different.

Interpretation: Under the first research objective, the evidence shows that there is significant influence of human capital development strategies on the competitiveness of SMPs. The ISAs expect that personnel deployed on an audit engagement must possess adequate technical training and proficiency as an auditor. This outcome can only be guaranteed through classroom teaching to qualify as a professional accounting through CPA or ACCA examinations, but more realistically through on-going continuing professional development programmes. The significant difference observed between SMPs that are part of AAN and those that are not implies that the former is investing significantly more on the developing technical competence in ISAs, IFRSs, tax and consulting which is one of the perceived benefits of membership (Bills, Hayne, \& Stein, 2018). The access to technical expertise within the AAN (often through a shared portal of technical materials based at the headquarters of the AAN) could lead to higher level of competitiveness and gaining more clients (Ahn, Akamah, Bills, \& Saunders, 2018). The data also reveals a significant difference in terms of annual development spend where AAN members spend on average USD 3000 per annum while non-members spend USD 1811. This is to some extent related to the previous point because higher investment in development programme is positively correlated with the time invested in different development/training activities in terms of technical and soft-skills. However, the lack of evidence of significant difference in terms of development days implies that both members and non-members are spending almost same quantum of time on development/training of their partners, supervisors and assistants.

4.8 Research objective (RO3) - to determine how human capital development strategies of SMPS in Uganda differ depending annual spend in development programmes

Interpretation: 60\% of the SMPs (75 of them) spend less than USD 2000 per annum on their human capital development programmes while 13\% (16 firms) spend above USD 4000 per annum as itemized under Appendix Table 5. The requirements for CPD are based on number of hours spent on structured and unstructured programmes. Structured programmes are often conducted externally by the regulator (ICPAU) or the particular SMP may choose other external channels so long as they obtain a certificate specifying the title of the seminar, workshop or conference and the quantum of CPD hours. Unstructured programmes include self-study and are often in-house. Structured programmes are more expensive that unstructured as there are fees to be paid for the former. The amount spent on development programmes could vary with the total staff complement at the SMP. The averages were calculated and it revealed that about USD 200 is spent per full-time professional, with the minimum at USD 26 and maximum of USD 643. The study did not drill down into the specific courses/programmes at each of the SMPs. Nonetheless, the regression of total full-time professional on annual spend revealed a coefficient of -4.58 . The interpretation is that for every additional full-time professional included in the SMP's development programmes, the annual spend reduces by USD 4.58 .

Identifying significant differences: From detailed under Appendix Table 6, all the regression results were significant in that the probabilities were less than the set $\alpha=0.05$ (which is the Type 1 error threshold). The overall computed $\mathrm{F}(4,119)=4.274, \mathrm{p}=0.003$. This means that the null hypothesis of no significant difference is rejected. Once more, Tukey's renown post-hoc HSD was deployed to identify where the differences lay. The Tukey's HSD pairwise comparisons were used with a studentized range critical value $(0.05,5,119)=3.9175$ as shown under Appendix Table 7. The post-hoc test revealed significant differences between Groups A and D, and then Groups A and E. There are significant differences in the composite Development index between SMPs that spend less than USD 1000 per annum and those that spend above USD 3000 per annum. There were no significant differences between SMPs of the other groups.

\section{Conclusion}

The level of competitiveness of the SMPs was categories into low, medium or high based on total clients billed per annum on Appendix Table 8 and then total annual revenue (in USD) on the Appendix Table 9. The following is a summary of the salient points from the study: 


\begin{tabular}{llll}
\hline \multicolumn{5}{l}{ Research findings } & Conclusions \\
\hline Human & capital & On average, SMPs & The academic and professional \\
strategy & had 11 full-time & qualifications are a foundation. This is \\
& professional staff, & reinforced by development of skills in \\
including $\quad$ the & various areas covering pillars of auditing, \\
& partners. A number & financial reporting, tax and consulting which \\
& of them are holders & are business lines from which most SMPs \\
& of Masters degree, earn money from. \\
& CPA and/or ACCA.
\end{tabular}

Recommendations

Effectiveness of Duration for human human capital capital development development strategy

Factors affecting competitiveness

Measures of $21 \%$ of SMPs have competitiveness

medium to high measure of competitiveness in terms of clients billed. $4 \%$ have medium to high measure in terms of annual revenue.

Impact of human The indices show capital development strategies competitiveness "fair to good" fit of the model linking development strategies to competitiveness.

Difference in Using ANOVA, human capital there is a significant development difference between strategies of AAN SMPs that are members and members of AAN those not members and those which are not.

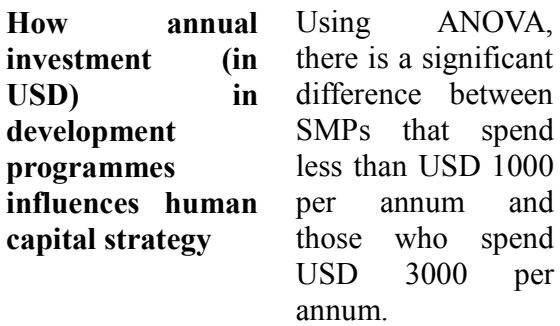

SMPs dedicated more time on developing skills in audit/assurance (ISAs) and financial reporting standards (IFRSs). These are the traditional core competence areas for most SMPs.

Development programmes that increase the client portfolio case and increase probability of pre-qualification and bid success are the winning strategy.

$79 \%$ of the SMPs (98 of them) billed less than 90 clients a year. This is categorised as "low" level of competitiveness. Three SMPs $(2 \%)$ earned between USD 1-2million per annum "medium competitiveness" and three SMPs (another 2\%) earned more than USD 2 million per annum "high competitiveness"

Quantity of human capital is important, but SMPs need to develop that human capital annually to comply with international standards.

SMPs need to increase the days from 13 to 20 in lime with the minimum threshold.

SMPs need to monitor these factors on an annual basis and observe the trend over a number of years.

SMPs should reap higher fees from their skilled professional staff. This will enable them gain higher fee revenue on their development spend investments.

The construct of Development explains SMPs should invest in both $44 \%$ of the variance in the construct of quantity and quality of human Competitiveness. capital programmes. development

In terms of the development spend, members spent USD 3000 per annum while non-members spent USD 1811 per annum. This is due to members having ready access to technical materials within their respective association or network. In terms of development days for each professional staff, there was no significant difference.

Total development spend varies with the Economical yet effective number of professional staff, number of technical materials can be days and the cost of the training. Average obtained from IFAC Global spend per professional staff ranged from Knowledge Gateway. However, USD 26-642, a very wide disparity. The SMPs should invest in firmresults of ANOVA indicate that specific innovations to "stand development spend per annum influences out of the crowd" and develop the human capital strategy that the SMP unique selling points that will deploy. enable them earn premium fees like the Big-4 counterparts.

SMPs worldwide, Uganda inclusive, indicated that there is regular pressure from their clients to maintain or reduce audit fees. In addition, SMP face a challenge of differentiating from competition (IFAC, 2017). The study reveals that SMPs earn more fees per client from consulting assignments, but lower number of clients. The study 
also highlights that $70 \%$ of the SMPs dedicated less than 16 days per annum per partner/professional staff on development programmes, which is lower than the recommended minimum of 20 days. The conclusion is thus that SMPs need to increase the days spent in continuing professional development (CPD) programmes, diversify into tax and consulting training plus selling/networking skills.

This study was meant to stimulate even more publications that are specific to SMPs and the following implications arise from this study:

Policy: The SMP Committee of the International Federation of Accountants has continued to develop technical materials that can be downloaded and used by SMPs as part of the human capital development. As ICPAU embarks on the development of its strategic plan for the years 2019-2023, it is evident that Quality Control for SMPs and Education Standards are two of the focus areas. Quality control can only be enhanced through human capital development through application of the education standards by partners, supervisory and assistant-level professional staff.

Firm-level: This empirical evidence shows that human capital development strategies influence the competitiveness. Each SMP should thus examine the mix of development programmes to include both technical and soft skills. In particular, although traditionally more days have been allocated towards ISAs and IFRSs, diversification into tax and consulting technical expertise can yield higher revenues.

Future research: Whereas SMPs spend money and accumulate CPD hours every year, progressing towards higher levels of competitiveness has remained a challenge. Future studies on SMPs could select a few cases for in-depth examination of the development curricula per full-time professional staff and trace how these translate into competitiveness measures like quality, bidding success, client satisfaction ratings and ultimately the topline (annual revenues) of the firm.

\section{References}

Abidin, S., \& Mohamad-Nor, M. N. (2015). Competition in Malaysian Audit Industry: What the Market is Telling Us? Mediterranean Journal of Social Sciences, 7(1), $306-311$. http://doi.org/10.5901/mjss.2016.v7n1p306

Ahn, J., Akamah, H. T., Bills, K. L., \& Saunders, K. K. (2018). Accounting Firm Association Membership and Audit Firm Growth. http://doi.org/10.2139/ssrn.3120493

Alderson, W., \& Cox, R. (1948). Towards a theory of marketing. Journal of Marketing, 13(2), 137-152.

Bapna, R., Langer, N., Mehra, A., Gopal, R., \& Gupta, A. (2013). Human Capital Investments and Employee Performance: An Analysis of IT Services Industry. Management Science, 59(November 2014), $641-658$. http://doi.org/10.1287/mnsc. 1120.1586

Berg, M. C. (2007). Continuing Professional Development-The IFAC Position 1. Accounting Education: An International Journal, 16(4), 319-327.

Bills, K. L., Cunningham, L. M., \& Myers, L. A. (2015). Small audit firm membership in associations, networks, and alliances: Implications for audit quality and audit fees. The Accounting Review, 91(3), 767-792. http://doi.org/10.2308/accr-51228

Bills, K. L., Hayne, C., \& Stein, S. E. (2018). A Field Study on Small Accounting Firm Membership in Associations and Networks: Implications for Audit Quality. The Accounting Review. http://doi.org/10.2308/accr-52003

Bills, K. L., Walton, S. M., Hayne, C., \& Stein, S. E. (2018). A Field Study on Small Accounting Membership in Associations and Networks: Implications for Audit Quality. http://doi.org/10.2308/accr-52003

Boud, D., \& Hager, P. (2012). Re-thinking continuing professional development through changing metaphors and location in professional practices. Studies in Continuing Education, 34(1), 17-30. http://doi.org/10.1080/0158037X.2011.608656

Bradley, S., Drapeau, M., \& DeStefano, J. (2012). The relationship between continuing education and perceived competence, professional support, and professional value among clinical psychologists. Journal of Continuing Education in the Health Professions, 32(1), 31-38. http://doi.org/10.1002/chp.21120

Clark, J. M. (1940). Toward a concept of workable competition. The American Economic Review, 241-256.

De Lange, P., Jackling, B., \& Basioudis, I. G. (2013). A framework of best practice of continuing professional development for the accounting profession. Accounting Education, 22(5), 494-497.

De Lange, P., Jackling, B., \& Suwardy, T. (2012). Continuing professional development in the accounting profession: Evidence from the Asia Pacific region. In AFAANZ 2012 (pp. 1-30). Accounting and Finance Association of Australia and New Zealand (AFAANZ). http://doi.org/10.1080/09639284.2013.824197

De Lange, P., Jackling, B., \& Suwardy, T. (2015). Continuing Professional Development in the Accounting Profession: Practices and Perceptions from the Asia Pacific Region. Accounting Education, 24(1), 41-56. http://doi.org/10.1080/09639284.2014.1002800

DeAngelo, L. E. (1981). Auditor size and audit quality. Journal of Accounting and Economics, 3(3), 183-199.

Djerdjouri, M., \& Kandiel, E. A. (2013). An Analysis of Productivity Changes of Chartered Accounting Firms in 
the UK, 2009-2012. Journal of Business and Accounting, 6(1), 120.

Fenwick, T. (2009). Making to measure? Reconsidering assessment in professional continuing education. Studies in Continuing Education, 31(3), 229-244.

Golnik, R. (2014). The Recruitment Process in Transnational Corporations. Polish Journal of Management Studies, 10(1), 189-197.

Hooper, D., Coughlan, J., \& Mullen, M. R. (2008). " Structural Equation Modelling: Guidelines for Determining Model Fit Structural Equation Modelling: Guidelines for Determining Model Fit. The Electronic Journal of Business Research Methods, 6(1), 53-60. http://doi.org/10.1037/1082-989X.12.1.58

Hu, L., \& Bentler, P. M. (1998). Fit indices in covariance structure modeling: Sensitivity to underparameterized model misspecification. Psychological Methods, 3(4), 424.

Hu, L., \& Bentler, P. M. (1999). Cutoff criteria for fit indexes in covariance structure analysis: Conventional criteria versus new alternatives. Structural Equation Modeling: A Multidisciplinary Journal, 6(1), 1-55.

ICPAU. (2017). ICPAU Accounting Firms, 2017. Retrieved February 3, 2018, from http://icpauportal.com/index.php/external_portal/firms

IFAC. (2012). Statements of Membership Obligations: ISBN: 978-1-60815-133-2 (Vol. 7).

IFAC. (2017). 2016 IFAC Global SMP Survey Report \& Summary. Retrieved from https://www.ifac.org/publications-resources/2016-ifac-global-smp-survey-report-summary

Kaspina, R. (2015). Continuing Professional Development of Accounting and Auditing: Russian Experienceand Challenges. Procedia - Social and Behavioral Sciences, 191, 550-553. http://doi.org/10.1016/j.sbspro.2015.05.110

Krejcie, R. V, \& Morgan, D. W. (1970). Determining sample size for research activities. Educational and Psychological Measurement, 38(1), 607-610. http://doi.org/10.1177/001316447003000308

Mahmood, F., Iqbal, N., \& Sahu, S. (2014). The Impact of Human Resource Management Practices on Employee Performance in Banking Industry of Pakistan. Euro-Asian Journal of Economics and Finance, 2 (1)(January), 86-99. http://doi.org/10.1016/j.sbspro.2014.11.178

Mao, J., Qi, B., \& Xu, Q. (2017). Does International Accounting Network Membership Affect Audit Fees and Audit Quality? Evidence From China. The International Journal of Accounting, 52(3), 262-278. http://doi.org/10.1016/j.intacc.2017.07.004

Mohamad-nor, M. N. (2015). The Structure of Malaysian Audit Market : From 2008 to 2010, 2003(April).

Ng'ang'a, E. M. (2014). An inquiry into the perceived skills gaps of professional accountants in Kenya: the case for innovative training and examination methodologies. Strathmore University.

O'Keefe, T. B., Simunic, D. A., \& Stein, M. T. (1994). The production of audit services: Evidence from a major public accounting firm. Journal of Accounting Research, 241-261.

Ofori, D., \& Aryeetey, M. (2011). Recruitment and Selection Practices in Small and Medium Enterprises: Perspectives from Ghana. International Journal of Business Administration, 2(3), 45-60. http://doi.org/10.5430/ijba.v2n3p45

Romanus, O. O., \& Arowoshegbe, A. (2014). The Challenges of Accounting Education: The Nigerian Experience. Accounting and Finance Research, 3(2), p129. http://doi.org/10.5430/afr.v3n2p129

Schumpeter, J. (1942). Creative destruction. Capitalism, Socialism and Democracy, 825.

Simunic, D. A. (1980). The pricing of audit services: Theory and evidence. Journal of Accounting Research, $161-190$.

Statista. (2017). Big Four: Revenues by Function, 2017. Retrieved January 28, 2018, from https:/www.statista.coin/statistics/250935/big-four-accounting-fmns

Svanström, T. (2016). Time pressure, training activities and dysfunctional auditor behaviour: evidence from small audit firms. International Journal of Auditing, 20(1), 42-51. http://doi.org/10.1111/ijau.12054

Webster-Wright, A. (2009). Reframing professional development through understanding authentic professional learning. Review of Educational Research, 79(2), 702-739.

Wessels, S. B. (2007). Accountants' perceptions of the effectiveness of mandatory continuing professional education. Accounting Education: An International Journal, 16(4), 365-378. 
APPENDIX

Table 1. Matrix of correlation between independent and dependent variables

\begin{tabular}{|c|c|c|c|c|c|c|c|c|c|c|c|c|c|c|}
\hline Variables & (1) & (2) & (3) & (4) & (5) & (6) & (7) & (8) & (9) & (10) & (11) & (12) & (13) & (14) \\
\hline (1) devp_isa & 1.000 & & & & & & & & & & & & & \\
\hline (2) devp_ifrs & 0.888 & 1.000 & & & & & & & & & & & & \\
\hline (3) devp_tax & 0.602 & 0.605 & 1.000 & & & & & & & & & & & \\
\hline (4) devp_consult & 0.470 & 0.442 & 0.688 & 1.000 & & & & & & & & & & \\
\hline (5) devp_itcaats & 0.451 & 0.416 & 0.415 & 0.321 & 1.000 & & & & & & & & & \\
\hline (6) devp_exams & 0.380 & 0.444 & 0.379 & 0.196 & 0.354 & 1.000 & & & & & & & & \\
\hline (7) devp_writing & 0.610 & 0.625 & 0.590 & 0.510 & 0.403 & 0.476 & 1.000 & & & & & & & \\
\hline (8) devp_selling & 0.458 & 0.447 & 0.545 & 0.556 & 0.426 & 0.311 & 0.714 & 1.000 & & & & & & \\
\hline (9) devp_leadership & 0.491 & 0.420 & 0.535 & 0.552 & 0.302 & 0.277 & 0.686 & 0.690 & 1.000 & & & & & \\
\hline (10) comp_portbase & 0.283 & 0.191 & 0.283 & 0.222 & 0.100 & 0.238 & 0.411 & 0.328 & 0.383 & 1.000 & & & & \\
\hline (11) comp_prequal & 0.299 & 0.256 & 0.282 & 0.110 & -0.025 & 0.121 & 0.280 & 0.059 & 0.246 & 0.408 & 1.000 & & & \\
\hline (12) comp_media & 0.291 & 0.273 & 0.219 & 0.197 & 0.100 & 0.106 & 0.271 & 0.171 & 0.233 & 0.313 & 0.411 & 1.000 & & \\
\hline (13) & 0.156 & 0.079 & 0.223 & 0.122 & 0.094 & 0.043 & 0.104 & 0.104 & 0.232 & 0.307 & 0.369 & 0.552 & 1.000 & \\
\hline $\begin{array}{l}\text { comp_bidsuccess } \\
\text { (14) comp_reqar }\end{array}$ & 0.050 & -0.003 & 0.214 & 0.339 & 0.080 & 0.179 & 0.178 & 0.248 & 0.398 & 0.418 & 0.219 & 0.276 & 0.417 & 1.000 \\
\hline
\end{tabular}

Source: Author

Table 2. Orthogonal varimax rotation (Eigenvalue $>1.0000$, Factor loading $>0.5000$ )

Observed variables for human capital development and competitiveness

1 Development: International Standards on Auditing (ISAs)

2 Development: International Financial Reporting Standards (IFRSs)

3 Development: Taxation

4 Development: Consulting

5 Development: IT and Computer-Aided Auditing Techniques (CAATs)

6 Development: Writing \& Presentation Skills

7 Development: Business Networking \& Selling Skills

8 Development: People \& Leadership Skills

9 Competitiveness: Portfolio Base of Clients

10 Competitiveness: Pre-qualification Listing

11 Competitiveness: Media \& Publicity

12 Competitiveness: Bid/Proposal Success Rate

13 Competitiveness: Quality Assurance Rating

Factor mean

$\%$ age of total variance

Cumulative \%age of total variance

\begin{tabular}{|c|c|c|c|}
\hline \multirow[b]{2}{*}{ Mean } & Eigenvalues & 5.228 & 1.467 \\
\hline & $\begin{array}{l}\text { Standard } \\
\text { deviation }\end{array}$ & $\begin{array}{c}\text { Development } \\
\text { Factor } \\
0.8245\end{array}$ & $\begin{array}{c}\text { Competitiveness } \\
\text { Factor }\end{array}$ \\
\hline 4.11 & 1.030 & & \\
\hline & 0.907 & 0.8327 & \\
\hline $\begin{array}{l}4.22 \\
3.65\end{array}$ & $\begin{array}{l}0.90 / \\
1.076\end{array}$ & 0.7506 & \\
\hline 3.07 & 1.177 & 0.6468 & \\
\hline & & 0.5418 & \\
\hline 2.78 & 1.227 & & \\
\hline 3.38 & 1.187 & 0.8112 & \\
\hline & & 0.7225 & \\
\hline 2.92 & 1.227 & & \\
\hline 3.05 & 1.147 & 0.6596 & \\
\hline 3.75 & 0.880 & & 0.5398 \\
\hline 4.13 & 0.928 & & 0.5302 \\
\hline 3.22 & 1.056 & & 0.5865 \\
\hline 3.80 & 0.954 & & 0.6767 \\
\hline 3.65 & 1.106 & & 0.6003 \\
\hline & & 3.90 & 3.71 \\
\hline & & $67.73 \%$ & $19.00 \%$ \\
\hline & & $67.73 \%$ & $86.73 \%$ \\
\hline
\end{tabular}

Source: Author 
Table 3: Linear regression of Development on Competitiveness

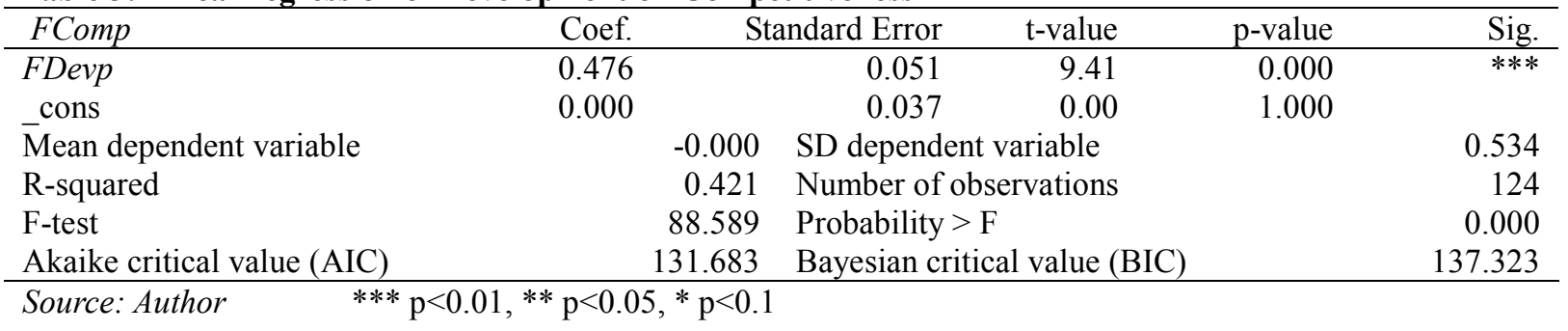

Table 4: Tukey's pairwise comparisons

\begin{tabular}{lrrrrr}
\hline \multicolumn{7}{c}{ Group means } & & & \\
\hline Variables & No membership & AAN member & Diff & HSD & Sig. \\
\hline Composite FDevp & -0.0773 & 0.4550 & 0.5323 & 4.1802 & $* *$ \\
Development spend & 1811.32 & 3000.00 & 1188.68 & 5.1091 & $* *$ \\
Assistant development days & 10.45 & 12.45 & 2.00 & 1.5367 & \\
Supervisor development days & 12.00 & 13.00 & 1.00 & 0.7545 & \\
Partner development days & 15.12 & 15.22 & 0.10 & 0.0729 \\
\hline
\end{tabular}

Table 5: Grouping of SMPs based on spend on development programmes

\begin{tabular}{llrr}
\hline Group & Spend per annum & Frequency & Proportion \\
\hline A & USD 0 - 1000 & 35 & $28.23 \%$ \\
B & USD 1001-2000 & 40 & $32.26 \%$ \\
C & USD 2001-3000 & 19 & $15.32 \%$ \\
D & USD 3001-4000 & 14 & $11.29 \%$ \\
E & USD $>4000$ & 16 & $12.90 \%$ \\
\hline & & 124 & $100.00 \%$ \\
\hline
\end{tabular}

Source: Author

Table 6: Multivariate regression results

\begin{tabular}{|c|c|c|c|c|c|c|c|}
\hline Group & FDevp & Coef. & & Standard Error & t-value & p-value & Sig. \\
\hline A & USD $0-1000$ & 0.000 & & 0.000 & 0.00 & 0.000 & $* * *$ \\
\hline B & USD 1001-2000 & 0.397 & & 0.160 & 2.47 & 0.015 & $* *$ \\
\hline $\mathrm{C}$ & USD 2001-3000 & 0.465 & & 0.197 & 2.36 & 0.020 & $* *$ \\
\hline $\mathrm{D}$ & USD 3001-4000 & 0.736 & & 0.219 & 3.36 & 0.001 & $* * *$ \\
\hline \multirow[t]{6}{*}{$\mathrm{E}$} & USD $>4000$ & 0.659 & & 0.209 & 3.15 & 0.002 & $* * *$ \\
\hline & cons & -0.367 & & 0.117 & -3.14 & 0.002 & $* * *$ \\
\hline & Mean dependent variable & \multicolumn{4}{|c|}{ SD dependent variable } & \multicolumn{2}{|r|}{0.728} \\
\hline & R-squared & & 0.126 & \multicolumn{2}{|c|}{ Number of observations } & \multicolumn{2}{|r|}{124} \\
\hline & F-test & & 4.274 & \multicolumn{2}{|c|}{ Probability > F } & \multicolumn{2}{|r|}{0.003} \\
\hline & Akaike critical value (AIC) & & 265.616 & \multicolumn{2}{|c|}{ Bayesian critical value (BIC) } & \multicolumn{2}{|r|}{279.717} \\
\hline
\end{tabular}

Source: Author $\quad * * * p<0.01,{ }^{* *} p<0.05, * p<0.1$

Table 7: Tukey's pairwise comparisons (critical value $=\mathbf{3 . 9 1 7 5}$ )

\begin{tabular}{|c|c|c|c|c|c|c|}
\hline \multicolumn{7}{|c|}{ Group means } \\
\hline Gro & up vs Group & First Group & Second Group & Mean Diff & HSD & Sig. \\
\hline A & $\mathrm{V} \quad \mathrm{B}$ & -0.3672 & 0.0293 & 0.3965 & 2.6132 & \\
\hline A & $\mathrm{V} \quad \mathrm{C}$ & -0.3672 & 0.0974 & 0.4646 & 3.0620 & \\
\hline A & V D & -0.3672 & 0.3685 & 0.7356 & 4.8482 & $* *$ \\
\hline A & V E & -0.3672 & 0.2917 & 0.6588 & 4.3421 & $* *$ \\
\hline B & $\mathrm{V} \quad \mathrm{C}$ & 0.0293 & 0.0974 & 0.0681 & 0.4488 & \\
\hline B & V D & 0.0293 & 0.3685 & 0.3391 & 2.2350 & \\
\hline B & V E & 0.0293 & 0.2917 & 0.2623 & 1.7289 & \\
\hline $\mathrm{C}$ & V D & 0.0974 & 0.3685 & 0.2710 & 1.7862 & \\
\hline $\mathrm{C}$ & V E & 0.0974 & 0.2917 & 0.1942 & 1.2800 & \\
\hline $\mathrm{D}$ & V E & 0.3685 & 0.2917 & 0.0768 & 0.5062 & \\
\hline
\end{tabular}

Source: Author $\quad * * * \mathrm{p}<0.01,{ }^{* *} \mathrm{p}<0.05, * \mathrm{p}<0.1$ 
Table 8: SMP competitiveness based on total clients billed per annum

\begin{tabular}{l|ccc|cc}
\hline Age of the SMP & $\begin{array}{c}\text { Low } \\
<90 \text { clients }\end{array}$ & $\begin{array}{c}\text { Medium } \\
90-180 \text { clients }\end{array}$ & $\begin{array}{c}\text { High } \\
>180 \text { clients }\end{array}$ & $\begin{array}{c}\text { Total number } \\
\text { of SMPs }\end{array}$ & $\begin{array}{c}\text { Percentage of } \\
\text { SMPs }\end{array}$ \\
\hline 1-5 years & 30 & 7 & 0 & 37 & $30 \%$ \\
6-10 years & 32 & 4 & 2 & 38 & $30 \%$ \\
11-15 years & 18 & 5 & 2 & 35 & $20 \%$ \\
16-20 years & 7 & 3 & 0 & 10 & $8 \%$ \\
$>$ 20 years & 11 & 2 & 1 & 14 & $12 \%$ \\
\hline Total number & 98 & 21 & 5 & & $100 \%$ \\
Percentage & $79 \%$ & $17 \%$ & $4 \%$ & & \\
\hline
\end{tabular}

Source: Author

Table 9: SMP competitiveness based on total annual revenue earned, in USD

\begin{tabular}{|c|c|c|c|c|c|}
\hline Age of the SMP & $\frac{\text { Low }}{<\mathrm{USD} 1 \mathrm{Mn}}$ & $\underline{\text { Medium }}$ & $\underline{\text { High }}_{\text {USD 2Mn }}^{\text {MSD }}$ & $\begin{array}{c}\text { Total number } \\
\text { of SMPs }\end{array}$ & $\begin{array}{c}\text { Percentage of } \\
\text { SMPs }\end{array}$ \\
\hline $1-5$ years & 37 & 0 & 0 & 37 & $30 \%$ \\
\hline $6-10$ years & 35 & 1 & 2 & 38 & $30 \%$ \\
\hline $11-15$ years & 24 & 1 & 0 & 35 & $20 \%$ \\
\hline $16-20$ years & 9 & 1 & 0 & 10 & $8 \%$ \\
\hline$>20$ years & 13 & 0 & 1 & 14 & $12 \%$ \\
\hline Total number & 118 & 3 & 3 & 124 & \\
\hline Percentage & $96 \%$ & $2 \%$ & $2 \%$ & & $100 \%$ \\
\hline
\end{tabular}

Figure 1. Path analysis for Development construct

Figure 2. Path analysis for Competitiveness construct

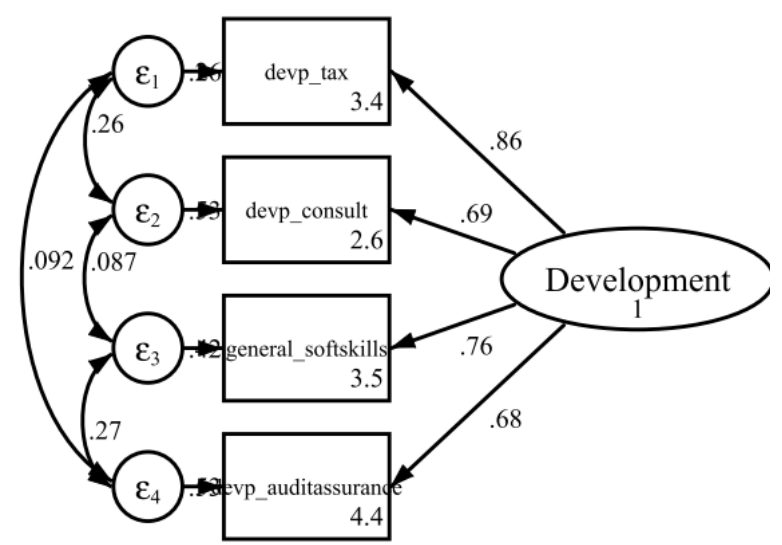

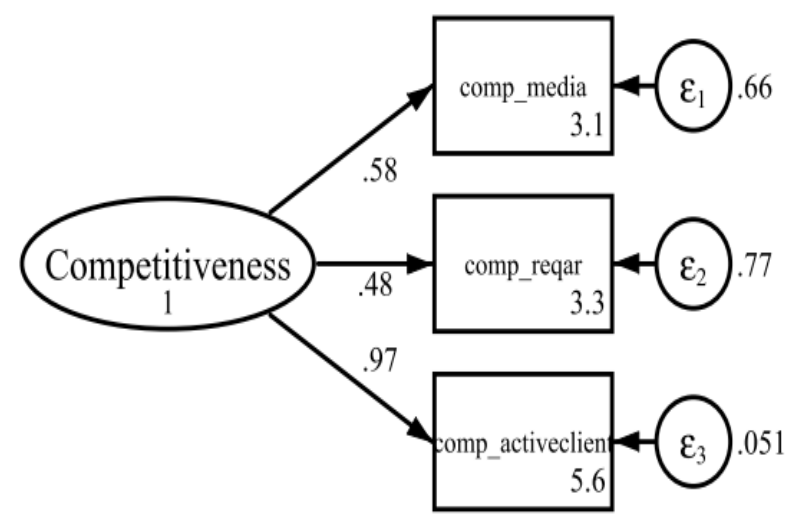

Figure 3. Path analysis for influence of Development construct on the Competitiveness construct

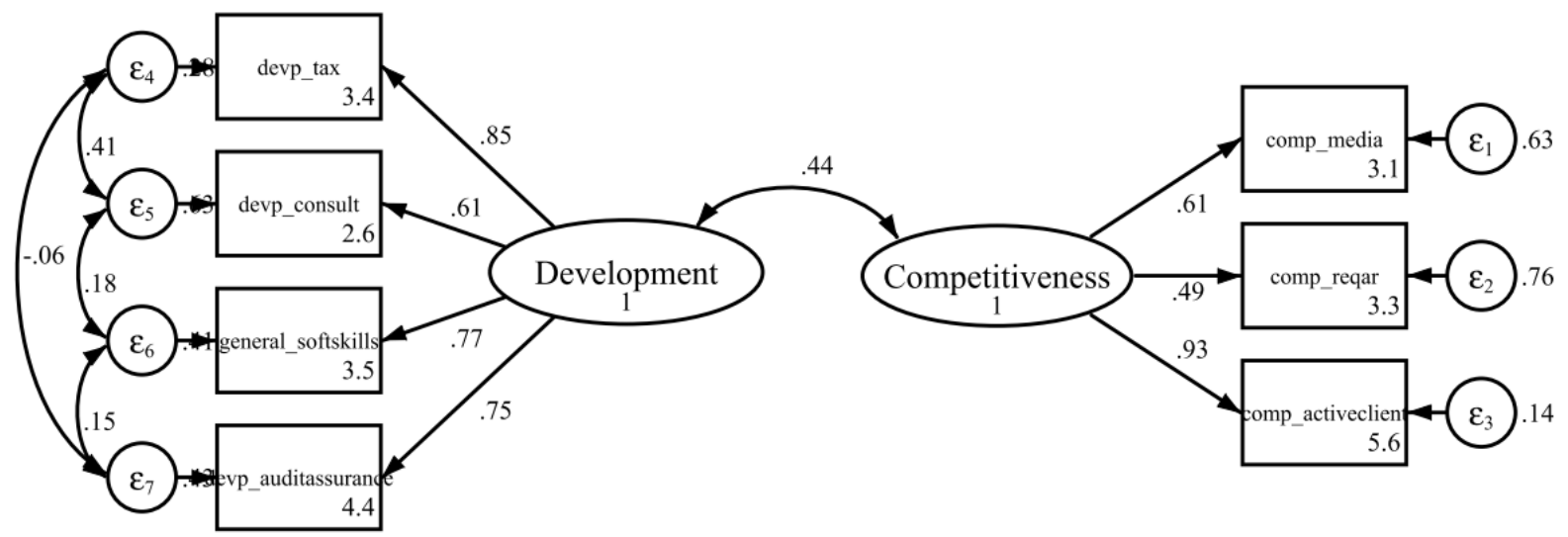


Figure 4. Leverage-Residuals plot of observed independent variable

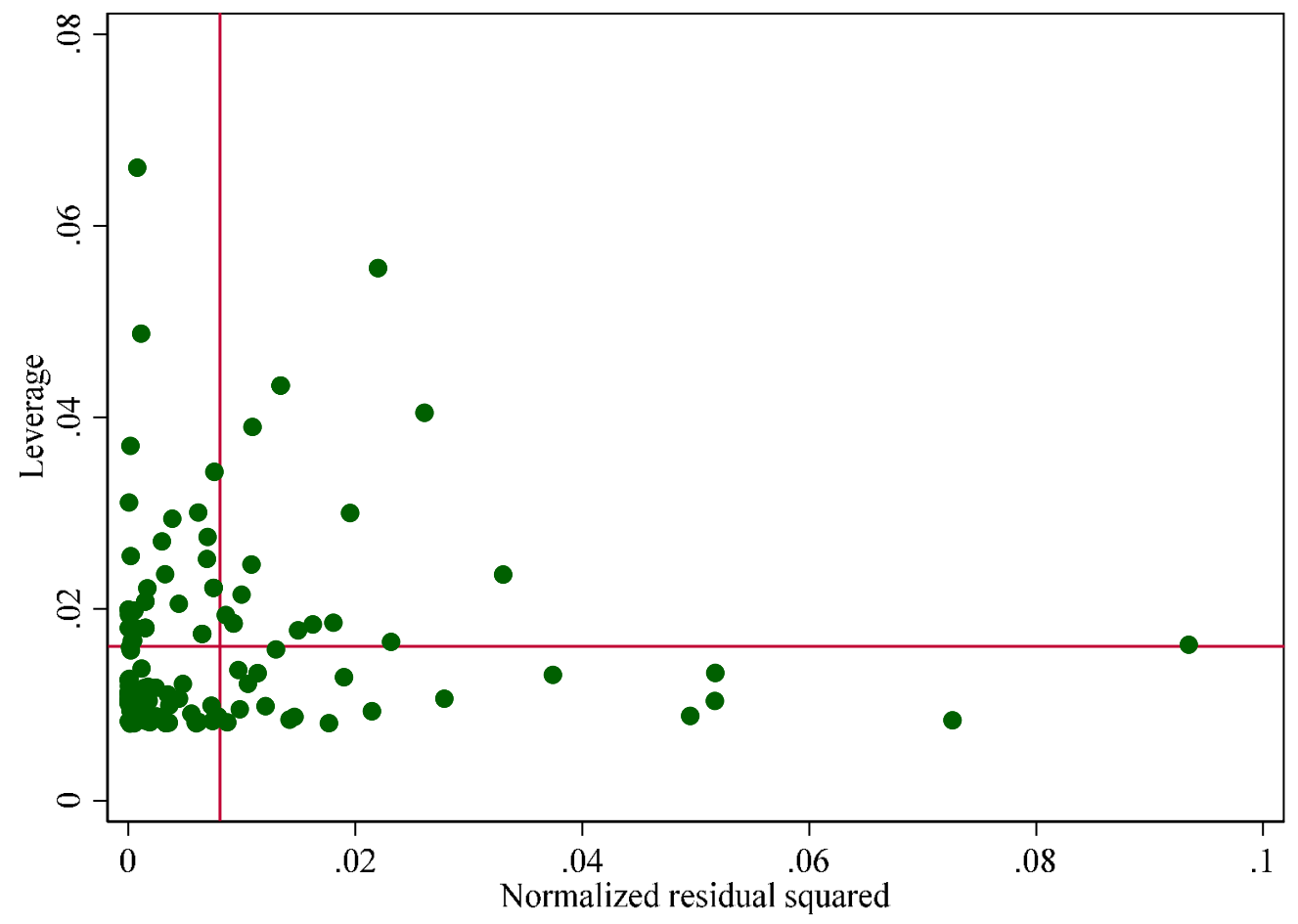

